NBER WORKING PAPER SERIES

\title{
THE TRADE-OFF BETWEEN WAGES AND EMPLOYMENT
} IN TRADE UNION OBJECTIVES

John H. Pencavel

Working Paper No. 870

NATIONAL BUREAU OF ECONOMIC RESEARCH 1050 Massachusetts Avenue

Cambridge MA 02138

March 1982

The research reported here is part of the NBER's research program in Labor Studies. Any opinions expressed are those of the author and not those of the National Bureau of Economic Research. Financial support has been provided by an NSF grant titled "Analysis of Trade Union Behavior." 


\author{
ABSTRACT \\ THE TRADE-OFF BETWEEN WAGES AND EMPLOYMENT \\ IN TRADE UNION OBJECTIVES \\ by \\ John H. Pencavel
}

This paper demonstrates that, contrary to a widely-held opinion, the determination of the goals of unions is fully amenable to empirical analysis. A characterization of the wage and employment-setting process in unionized markets is adopted and its qualitative implications examined. The first-order condition for this model is fitted to timeseries data on the newspaper industry from ten cities. The International Typographical Union's objective function reveals very restricted opportunities for substituting wages for employment in response to a change in the slope of the employer's labor demand function. Larger union locals place greater emphasis on wages versus employment than smaller union locals.

Professor John Pencave1 Department of Economics Stanford University Stanford, Ca. 94305

(415) 497-3981 


\section{Introduction}

There is now a considerable volume of evidence to suggest that unionized labor markets operate differently in a number of respects from non-unionized labor markets. However, in general, these findings have been reported with little attempt to relate these empirical regularities to the objectives of and constraints on the decision-making units involved. Consequently, our understanding of "what may trade unions maximize?" has advanced only a trifle from the time that John Dunlop [1944] first raised the question almost 40 years ago. The prevailing opinion appears to be that the problem of modelling trade union behavior is "virtually intractable" [Johnson, 1975]. The purpose of this paper is to belie this notion. We adopt a characterization similar to Dunlop's for the determination of wages and employment in unionized markets and we apply this model to a particular institutional setting. Our objective is not to endorse the specific model of the trade union outlined here, but simply to demonstrate that the investigation of union goals is fully amenable to empirical analysis.

The data examined here describe the wages and employment of members of the International Typographical Union for ten cities over the 20 years from 1946 to 1965. This is a truly extraordinary union whose features are well suited to the particular model outlined. Before the dramatic technological changes of the last 15 years, the union occupied a very powerful bargaining position with newspaper firms and, therefore, there is good reason for interpreting the movements of wages and employment of these typographers as reflecting the constrained objectives of 
the union. This represents a maintained hypothesis in this paper and, while some observers of this institutional setting may question this judgement, it is not evident that the sort of abstraction involved here is any more demanding of empirical phenomena than are the economist's conventional models of the firm or of the family. Moreover, good reason exists for investigating the role of the ITU in view of the unsatisfactory state of our understanding of the pattern of wages in the printing industry which is based on research that has avoided explicit modelling of the behavior of the union. For instance, in the literature that seeks an explanation for the movement in money wage rates over time, the sort of multiple regression equation that is preferred for most industries always performs lamentably for the printing industry 1 / In addition, the variation in the wage rates of typographers across cities is much greater than the typical geographical differentials for a given occupation and this has never been satisfactorily accounted for $\underline{2}$ Naturally one is led to wonder whether a better understanding of the union would provide the key to an explanation of these features of the printing industry.

In this paper the union is characterized as maximizing an objective function that contains wage rates and employment as arguments and as being constrained by a trade-off between these two variables given by the employer's labor demand function. This model which offers a determinate solution to union-management bargaining was articulated most fully by William Fellner [1947] and Allan Cartter [1959]. As a theory of the determination of wages and employment in unionized markets, it is 
clearly deficient in not explaining how a position of disagreement at the opening of the collective bargaining process converges over time into a mutually acceptable contract. Moreover, as Leontief [1946] and Fellner [1947] made clear, the solution to the bargaining process provided by this model lies inside the payoff frontier and thus it is an inefficient contract from the point of view of the two parties involved. However, the standard of efficiency used here is one that presumes the absence of transactions costs to negotiating an agreement and the empirical relevance of this standard for a union-management bargaining situation should not be taken for granted. That is, it is not evident that collective bargaining procedures provide incentives for the parties to reveal their respective valuations and, in fact, each party's objective function tends to be camouflaged by a veil of threats, bluffs, and deceptions. In such circumstances when each party's perception of its opponent's payoff function is distorted, there is no guarantee that the Pareto frontier (defined as excluding these negotiation costs) will be reached and so there seems no compelizing reason either to presume that union-management contracts are efficient in this sense or to presume that they are not.

This Fellner-Cartter model is outlined in the following section and, since there has been little attention addressed to the issue, the qualitative implications of the model are discussed. Section III presents a brief description of the ITU and the American newspaper industry and of the data used in this study. Estimates of the objective functions of the ITU locals are presented in section IV. 


\section{Conceptual Framework}

Our starting point is a firm that hires labor and $n$ other inputs at given prices to produce an output at minimum cost. The cost function summarizing this behavior is

$$
C=C\left(w, r_{1}, r_{2}, \ldots, r_{n}, X\right)=C(w, r, X),
$$

where $w$ is the wage rate, $r_{i}$ the price of input $i$, and $X$ the level of output. C is assumed to be smooth and fully differentiable and is a linearly homogeneous concave function of all input prices. The costminimizing level of employment, $L$, is determined from the cost function by simple differentiation:

$$
L(w, r, X)=\frac{\partial C(w, r, X)}{\partial w} \equiv C_{w}
$$

The workers are organized in a trade union whose leader takes account of the welfare of all its members as represented by the following quasi-concave objective function:

$$
U=g(w, I, Y)
$$

where $U$ is assumed to be strictly increasing in the wage rate (w) and in employment (L). Variables that affect union preferences, but are exogenous to the union are indexed by $Y$. These might include the price level of commodities consumed by union members, the wage received by a comparison group of workers, or the level of unemployment benefits. This objective function, equation (2), includes as special cases the 
wage bill as proposed by Dunlop, rents from unionization as proposed by de Menil [1971] and Rosen [1970], and expected per member utility as proposed by Farber [1978], McDonald and Solow [1981], and Oswald [1982] •

The union selects $w$ and $I$ to maximize its objective function, equation (2), subject to the choice of $w$ and $L$ being restricted by the employer's labor demand function, equation (1). The situation in which the union determines the wage rate and then leaves the employer to determine employment through equation ( 1 ) is, of course, consistent with this model. The first-order condition for a maximum is

$$
\frac{g_{1}}{g_{2}}=-\frac{\partial C_{w}(w, r, X)}{\partial w} \equiv s(w, r, X),
$$

where $g_{1} \equiv \partial U / \partial w>0$ and $g_{2} \equiv \partial U / \partial L>0$ or the marginal rate of substitution of wages for employment in the union's objective function equals the slope (s) of the firm's labor demand function. The secondorder condition for a maximum may be written as

$$
\Delta=-\sigma^{-1} w^{-1} g_{1}(s w L-1+1)-g_{2} s_{w}
$$

where $s_{w}=\partial s / \partial w, s w L^{-1}$ is the wage elasticity of the firm's labor demand function, and $\sigma$ is the elasticity of substitution between wages and employment in the union's objective function. The reduced form equations may be derived from equations (1) and (3) and they express wage rates and employment as functions of all the exogenous variables:

$$
W=\phi_{1}(Y, r, X) ;
$$




$$
L=\phi_{2}(Y, r, X)
$$

These reduced form equations and the marginal rate of substitution equation (3) are invariant under positive monotonic transformations of the union's objective function.

The qualitative content of this model of unionism is assessed by determining the signs of the partial derivatives of equations (5) and (6). In fact, without specifying particular expressions for the objective and constraint functions, all that can be said about the signs of these derivatives is that the sign of $\partial L / \partial Y$ must be opposite that of $\partial w / \partial Y$ : an increase in $Y$ alters the objective function, but does not disturb the constraint $C_{W}$ so if the union opts for an increase in wage rates then this must be accompanied by a decrease in employment. Other than this restriction across equations (5) and (6), the sign of each of the partial derivatives is ambiguous and in this sense the model is empty of qualitative implications $\underline{3}$ / This is not surprising in view of the theorem of conjugate pairs [Archibald, 1965], but it is odd that a model with so little qualitative content should have provoked such an extensive debate as that which arose over whether or not the trade union can be portrayed as maximizing anything $\frac{4}{4}$

The dual of this problem describes the union as selecting $w$ and $L$ to minimize the parameters of the labor demand function $C_{\mathrm{w}}=\mathrm{L}(\mathrm{w}, \mathrm{r}, \mathrm{X})$ subject to a prescribed value of the objective function $U^{0} \geq g(W, L, Y)$. Naturally, the first-order condition for this problem is again given by equation (3) which may be solved jointly with the 
constraint to yield "utility-constant" reduced form equations for wages and employment:

$$
\begin{gathered}
w=\psi_{I}\left(Y, r, X, U^{0}\right) \\
L=\psi_{2}\left(Y, r, X, U^{0}\right) .
\end{gathered}
$$

The derivatives of these equations can be related to those of equations (5) and (6) in Slutsky-type fashion, but, unless further restrictions are placed on the objective function or on the constraint function, the "utility-constant" derivatives (such as $\partial \psi_{1} / \partial Y$ and $\partial \psi_{1} / \partial X$ ) cannot be signed.

Instead of dwelling on the dearth of qualitative statements that can be made, consider what restrictions on the model will yield unambiguous implications. For instance, suppose labor is not an inferior input (so $\partial \mathrm{C}_{\mathrm{w}} / \partial \mathrm{X}>0$ ) and suppose that the union's objective function is strongly separable in wages and employment (so $g_{12}=0$ ). Then, provided an increase in output does not increase the slope of the labor demand function with respect to wage rates (that is, provided $\left.\mathbf{s}_{X} \leq 0\right)$, an increase in output will induce an increase in the optimal wage rate. On the corresponding set of assumptions, an increase in the price of an input that is a substitute for labor will induce an increase in the optimal wage rate. In these two cases, whether or not optimal employment also increases depends upon the magnitude of the slope of the labor demand function with respect to wages. Alternatively, suppose the union maximizes the total rents from unionization. Once again, if labor 
is not an inferior input and provided an increase in output does not increase the slope of the labor demand function, then an increase in output will induce an increase in the optimal wage rate. However, so little is known about the nature of the union's preferences for wages and employment that we are in no position to assess the empirical relevance of alternative prior restrictions on the union's objective function. For example, Cartter's $|1959|$ conjecture that the elasticity of substitution between wages and employment in the union's objective function is very low $5 /$ has never been confronted with the evidence although the limiting case of this hypothesis--that wages and employment are combined in fixed proportions--would considerably simplify models of unionized labor markets.

\section{The Institutional Background and the Data}

The data used to estimate the union's objective function consist of annual observations on wages, employment, and other variables describing the members of the International Typographical Union and the newspaper industry in ten American cities from 1946 to 1965 . The ITU is the quintessential democratic union where the leaders exercise very little discretionary authority, where the perquisites of being an official are few, where the rank-and-file are intimately involved in the. management of the union, and where there are no important skill differentials within the union $6 /$ Consequently, an objective function such as equation (2) that does not differentiate between the interests of the leadership and of the rank-and-file or between various groups within the 
rank-and-file is well suited to the ITU. Moreover, it is evident from the ITU's well-known concern for the employment effects of new technology that the employment of its members occupied a very important place in its objectives. On the other hand, the popular portrayal of the union as relentlessly opposing new composing methods is something of a caricature. There have been occasions on which the union has sponsored inventions and it established its own research and development laboratory and staff in the 1950s. The more accurate description is that the ITU adapted to and controlled the new technology up until the mid-1960s If In the period before the dramatic technological changes that have taken place in the newpaper industry in the last fifteen years or so, the ITU had clearly established a dominant bargaining relationship with the employers: collective bargaining took place at the local level where the ITU operated a closed shop requiring every worker in the composing room, including the foreman, to be a member of the union. Newspapers were extremely vulnerable to an interruption in production and, in fact, for the ten union locals in the years analyzed below, no strikes took place. The ITU was a highly sophisticated union and very mindful of the competitive environment in which newspapers operated. Wage increases not matched by increases in productivity would translate into newspaper price and advertising rate increases that, other things equal, would harm the newspaper's total revenue and ultimately discourage ITU employment. 
The data most appropriate for a study of this kind describe the production processes of a particular newspaper and, in fact, such data have been obtained for the Cincinnati Post. $8 /$ For Cincinnati, w stands for the hourly wage for journeymen printers at the Post and $I$ is the number of full-time typographical workers in the Post composing room. In 1958, the Post merged with the Cincinnati Times-Star and the ITU members of the Times-Star chapel were absorbed into the Post composing room. The primary problem presented by extending the study to other cities is the difficulty of obtaining employment data. The Pypographical Journal, the union's publication, supplies data on local union membership, but these figures will include INU members employed in commercial (book and job) printing establishments. Typically, major book and job establishments are located in very large cities so, if we avoid these cities, a much closer correspondence between local union membership and newspaper employment is reached. Therefore, for nine other cities, the data on $L$ represent local union membership. Average values of $W$ and $L$ over the years $1946-65$ for the ten cities are given in Table I together with other characteristics of these cities. The cities range from Columbus, Ohio, that had a mean journeyman membership of just over 600 in these years to Fond du Lac, Wisconsin, which was about one-fifteenth the size of Columbus. Average money wages ranged from a high of $\$ 2.94$ in Columbus to $\$ 2.17$ in Dubuque. In fact, the wages of typographers vary markedly across all cities in the United States and a thorough explanation for these differentials has yet to be provided. For the ten cities listed in Table I 
Table I

Mean Values of Variables for Ten Cities

Averaged Over the Years 1946-1965

\begin{tabular}{|c|c|c|c|c|c|c|}
\hline & & $\underline{w}$ & $w / p$ & $\underline{L}$ & $\underline{x}$ & 1960 population \\
\hline 1 & Cincinnati $^{\mathrm{m}}, \mathrm{OH}$ & 2.88 & 3.51 & 172 & 18.8 & 503 \\
\hline 2 & Augusta, GA & $2 \cdot 35$ & 2.96 & 56 & $19 \cdot 5$ & 71 \\
\hline 3 & Columbia, SC & 2.42 & 2.99 & 105 & $23 \cdot 6$ & 97 \\
\hline 4 & Dubuque $^{\mathrm{m}}$, IO & 2.17 & 2.73 & 68 & $9 \cdot 3$ & 57 \\
\hline 5 & Memphis, TN & 2.84 & 3.46 & 323 & $42 \cdot 5$ & 498 \\
\hline 6 & Fond du Lac, WI & 2.41 & 2.96 & 41 & 7.8 & 33 \\
\hline 7 & Louisville, KY & 2.89 & 3.44 & 397 & $43 \cdot 7$ & 391 \\
\hline 8 & Elmira, $N Y$ & 2.63 & 3.15 & 120 & $16 \cdot 3$ & 47 \\
\hline 9 & Columbus ${ }^{\mathrm{m}}, \mathrm{OH}$ & 2.94 & $3 \cdot 58$ & 602 & 51.0 & 471 \\
\hline 10 & Albany $^{m}, N Y$ & $2 \cdot 78$ & $3 \cdot 38$ & 596 & 30.8 & 130 \\
\hline & All ten cities pooled & 2.65 & 3.24 & 262 & $27 \cdot 1$ & 230 \\
\hline
\end{tabular}

Notes: The superscript " $m$ " following four of the cities identifies those cities in which a newspaper merger took place between newspapers during these years. The average hourly wage scale for journeymen is given by $w$ and $w / p$ is $w$ deflated by the consumer price index. L denotes employment at the Post for Cincinnati and it represents local union membership for the other cities. The data on $w$ are from issues of the ITU Bulletin while union membership data come from the Typographical Journal. The Post's advertising linage (in thousands) in April is listed in the column headed $X$ while for the other cities $X$ is total linage sold by all the local daily newspapers. This information on $X$ comes from issues of Editor and Publisher, a trade magazine. A rough index of potential readership is provided by the numbers on the population (in thousands) of each city in 1960. These population figures are taken from Table 30 of the 1960 Census of Population, Vol 1, Characteristics of the Population, Part $\bar{t}$, U.S. Summary. 
over these years, there were strong positive trends in both real wages and employment, but virtually no cyclical movements in these variables, a finding consistent with the belief that unionism tends to insulate these labor market variables from cyclical movements in economic activity.

\section{Empirical Results}

One way of implementing the model of unionism outlined above is to posit particular functional forms for the union's objective function, equation (2), and for the firm's labor demand function, equation (1), and then to estimate the implied reduced form equations for wages and employment, equations (5) and (6). This procedure has been applied in previous work $9 /$ and it possesses the attractive feature of permitting simulation exercises on the reduced form equations. On the other hand, the closed form solution of the reduced form system can be obtained only if relatively simple expressions are specified for the union's objective function and for the labor demand function. Hence, if we limit ourselves to reduced form estimation, then this rules out some interesting general forms for the objective and constraint equations. Consequently, a different course is pursued here, one of estimating the marginal rate of substitution equation (3). This has the computational advantage of requiring nothing more than standard two-stage least-squares.

Suppose the union's objective function takes the following form where $p$ denotes the consumer price index, a measure of the price level of consumer goods purchased by union workers: 


$$
\begin{aligned}
U\left(\frac{W}{p}, I\right) & =\mu(1+\lambda)^{-1}\left[\left(\frac{w}{p}-\gamma\right)^{1+\lambda}-1\right]+(1-\mu)(1+\eta)^{-1}\left(L^{I+\eta}-1\right) \\
& =k+\mu(1+\lambda)^{-1}\left(\frac{w}{p}-\gamma\right)^{1+\lambda}+(1-\mu)(1+\eta)^{-1} L^{1+n}
\end{aligned}
$$

where $k=-\left[\mu(1+\lambda)^{-1}+(1-\mu)(1+n)^{-1}\right]$ and where $0<\mu<1$ and $w / p>\gamma$. This objective function is quasi-concave if the following expression is negative:

$$
\mu(1-\mu)\left(\frac{w}{p}-\gamma\right)^{\lambda-1} L^{n-1}\left(\lambda(1-\mu) L^{n-1}+n \mu\left(\frac{w}{p}-\gamma\right)^{\lambda-1}\right),
$$

a sufficient (but not necessary) condition for which being that both $\lambda$ and $n$ are negative. This strongly separable function, equation ( 7 ), is the addilog augmented by the parameter $\gamma$ that provides a reference point for real wages. This function has the appealing feature of nesting some interesting special cases. For instance, consider $\lambda=n \rightarrow-1$. Then the objective function may be written as follows:

$$
U\left(\frac{w}{p}, I\right)=\mu \log \left(\frac{W}{p}-\gamma\right)+(I-\mu) \log L,
$$

and if, futhermore, $\mu=0.5$ and $\gamma$ equals the competitive real wage, then this objective function is a transformation of the rents from unionization, an objective discussed by DunIop [1944], Rosen [1970], and de Menil [1971]. If $\lambda=n+-1, \mu=0.5$ and $\gamma=0$, the objective function is a transformation of Dunlop's wage bill maximand. Or if $\gamma=0$ and $\lambda=n \neq-1$, the objective function is a transformation of 
the constant-elasticity-of-substitution function, but otherwise the elasticity of substitution $(\sigma)$ between wages and employment in the union's objective function is not constant and, in particular, $\sigma$ is given by the following expression:

$$
\sigma=-\left[\frac{\mu\left(\frac{w}{p}-\gamma\right)^{\lambda}\left(\frac{W}{p}\right)+(I-\mu) L^{I+\eta}}{\lambda(I-\mu)\left(\frac{W}{p}-\gamma\right)^{-1}\left(\frac{w}{p}\right) L^{I+\eta}+\eta \mu\left(\frac{W}{p}-\gamma\right)^{\lambda}\left(\frac{W}{p}\right)}\right] \text {. }
$$

Clearly, unless the parameters assume the particular values discussed above, the union's preferences for wages vis-à-vis employment cannot be described fully by a single parameter and the value of the substitution elasticity depends on the particular combination of wages and employment being evaluated.

With this augmented addilog objective function, the natural logarithm of the marginal rate of substitution equation ( 3 ) is as follows:

$$
\lambda \log \left(\frac{w}{p}-\gamma\right)+\log \left(\frac{\mu}{L-\mu}\right)-\log p-\eta \log L=\log s
$$

where, as before, $s$ is the slope of the firm's labor demand function. The empirical implementation of this equation requires an expression for the slope of the labor demand function and this has been assumed to be $s=e^{\alpha X} / r$ where $X$ indexes output $10 /$ and $r$ denotes the price of newsprint (in hundreds of dollars per short ton) as quoted in national markets. Newsprint is a very important input into newspaper production and previous work indicated that the ratio of wages to the price of newsprint exercised a highly significant influence upon typographer 
employment. The specification here builds upon this finding by allowing the slope of the labor demand function to depend upon output $(X)$ as well. Integration will reveal that very general labor demand functions and cost functions (including cost functions exhibiting decreasing or constant or increasing returns to scale) are consistent with this expression for sill In addition, the reference parameter for real wages $(\gamma)$ is specified not as a fixed constant but as a constant proportion of the real wages of another group of workers, say, $\gamma=\beta\left(w^{a} / p\right)$, a popular special case of this being $\beta=1$. With these assumptions concerning $s$ and $\gamma$, the previous equation may be written

(9) $\log \left(\frac{w}{p}\right)=\log \left\{\beta\left(\frac{w^{a}}{p}\right)+\exp \left[\frac{1}{\lambda} \log \left(\frac{1-\mu}{\mu}\right)+\frac{1}{\lambda} \log \left(\frac{p}{r}\right)+\frac{\eta}{\lambda} \log L+\frac{\alpha}{\lambda} X\right]\right\}$ and, after a stochastic error term is added to the right-hand side, this equation may be fitted by nonlinear two-stage least-squares methods [Amemiya, 1974] where employment is treated as endogenous 12/

Table II presents the results from fitting equation (9) to the pooled 182 observations on all ten union locals together. To serve as a reference wage series $\left(w^{a}\right)$, both the average hourly earnings of nonsupervisory workers in retail trade (who are almost wholly nonunionized) and the average hourly earnings of production workers in manufacturing industry were used. These two wage series move together over the years from 1946 to 1965 so there is little difference between 
Table II

Estimates of the Marginal Rate of Substitution Equation (9) (standard errors in parentheses)

\begin{tabular}{lccccccc} 
Line & \multicolumn{1}{c}{$\underline{\underline{B}}$} & $\underline{\mu}$ & $\underline{\lambda}$ & $\underline{\eta}$ & $\underline{\alpha}$ & $\underline{\sigma}$ & $\underline{\text { see }}$ \\
(i) & 1.257 & 0.195 & -0.994 & -0.227 & 0.001 & 0.361 & 0.061 \\
& $(0.081)$ & $(0.054)$ & $(0.210)$ & $(0.065)$ & $(0.003)$ & $(0.085)$ & \\
(ii) & 1.290 & 0.111 & -0.591 & -0.415 & 0.015 & 0.580 & 0.468 \\
& $(0.132)$ & $(0.051)$ & $(0.173)$ & $(0.117)$ & $(0.006)$ & $(0.148)$ & \\
(iii) & 1.300 & 0.337 & -0.838 & -0.111 & 0.001 & 0.402 & 0.040 \\
& $(0.117)$ & $(0.180)$ & $(0.211)$ & $(0.191)$ & $(0.003)$ & $(0.061)$ & \\
(iv) & 0.774 & 0.356 & -4.624 & -0.163 & -0.086 & 0.131 & 0.137 \\
& $(0.437)$ & $(1.163)$ & $(10.365)$ & $(1.288)$ & $(0.255)$ & $(0.286)$ & \\
(v) & 1.061 & 0.709 & -2.406 & 0.063 & -0.020 & 0.191 & 0.031 \\
& $(0.175)$ & $(0.417)$ & $(0.940)$ & $(0.514)$ & $(0.011)$ & $(0.061)$ & \\
(vi) & 1.525 & 0.513 & -0.311 & 0.157 & 0.001 & 0.707 & 0.041 \\
& $(0.205)$ & $(0.286)$ & $(0.284)$ & $(0.293)$ & $(0.005)$ & $(0.330)$ &
\end{tabular}

Notes: The standard error of the regression is given by "see." The mean and standard deviation of $\log (\mathrm{w} / \mathrm{p})$ over all observations are 1.165 and 0.145 respectively. The mean and standard deviation of $\log \mathrm{L}$ are 5.167 and 0.946 . The elasticity of substitution $(\sigma)$ between wages and employment is evaluated for all of the entries above at the overall mean values of real wages and employment, namely, 3.24 and 262 respectively and with $\mathrm{w}^{\mathrm{a}} / \mathrm{p}=1.66$, its mean value. 
the two sets of estimates. The results presented in Table II correspond to the use of the wage of retail trade workers for $w^{a}$. According to the estimates in line $(i), \lambda$ is very close to -1 and $B$ is not appreciably greater than unity so that the first term in the union's objective function approximates the expression $\mu \log \left(\frac{w}{p}-\frac{w}{p}\right)$. However, with $\mu$ significantly different from 0.5 and $n$ significantly different from unity judged by conventional criteria, the data do not seem to be consistent with an objective function that takes the form of the rents from unionization. Equation ( 9 ) is normalized with respect to the logarithm of real wages, but the instrumental variables estimator of a nonlinear equation is not invariant to the variable selected for normalization. Consequently, the estimates in line (ii) of Table II report the effects of rewriting equation (9) so that $\log I$ constitutes the left-hand side variable and where the same set of instruments are used for $\log (w / p)$. These estimates do not differ appreclably from those in line (i) except that $\lambda$ and $\eta$ are closer to being equal to one another. However, $B$ remains significantly different from unity so that a simple constant-elasticity-of-substitution (CES) function does not appropriately describe this union's objectives.

The estimates reported in line (iii) correspond to fitting equation (9) after augmenting it with a vector of dumm variables for each of the union locals. In particular, suppose the slope of the labor demand function is $s=\exp \left(\alpha X+\sum_{i} \delta_{i} z_{i}\right) / r$ where $z_{i}$ takes the value of unity for the ith union local and of zero otherwise. Then equation (9) is respecified to include the terms $\sum_{i} \delta_{i} Z_{i} / \lambda$ within the square 
brackets. The resulting estimates of the objective function parameters do not differ in any meaningful sense from those in the previous lines. In particular, the estimates are not consistent with the special functional forms that are nested in our specification, namely, the wage bill maximand, the rents from unionization, and the CES function.

Line (iv) of Table II reports the estimates of equation (9) that treat output (in addition to employment) as endogenous. 13/ The most noticeable feature of these estimates is the increase in the standard errors over those in previous lines and no doubt this reflects, in part, the inadequacy of our instrumental variables. These estimates testify to the fact that confident inferences from these results about the nature of this union's objectives are simply unwarranted at this stage of the research. $14 /$

To this point, although differences among the ten cities have been permitted in the slope of the labor demand constraint, the parameters of ITU's objective function have been assumed to be the same for all ten locals. Previous work [Dertouzos and Pencavel, 1981] suggested that the objective function probably varied with the size of the union so this sample of ten ITU locals was split into two categories of five relatively small union locals and five relatively large union locals. The large union locals consist of Cincinnati, Memphis, Louisville, Columbus, and Albany and over the 1946-65 period their average real wages ranged from 3.38 to 3.58 , their employment averaged 418 , and they operated in the larger cities with an average 1960 population of almost 400,000 people (see Table I). The small union locals are those in 
Augusta, Columbia, Dubuque, Fond du Lac, and Elmira and in these years they had a lower average real wage (namely, 2.96), their average employment was 78 , and they were located in the smaller cities with an average population in 1960 of 61,000 people. On all three criteria (real wages, employment, and population), the smallest of the group of relatively large union locals was greater than the largest of the group of relatively small union locals. Then equation (9) augmented by a vector of union dummy variables (i.e., by the terms $\sum_{i} \delta_{i} z_{i} / \lambda$ in the notation introduced earlier) was fitted to each of the two groups of union locals. The results are presented in lines ( $v$ ) and (vi) of Table II, the relatively large union locals in line $(v)$ and the relatively small union locals in line (vi).

Although the estimated standard errors caution against confident inferences, the larger ITU locals tend to place slightly more weight on "supernumerary" real wages relative to employment (as given by $\mu$ ). This may be the consequence of the greater alternative employment possibilities (especially in commercial printing) available in the bigger cities where the larger unions were located. The smaller union locals reveal less restricted opportunities of substituting real wages for employment in their objectives (as given by $\sigma$ ) than the larger union locals and, indeed, for the smaller union locals the hypothesis of a unitary substitution elasticity cannot be rejected. For the larger union locals' estimates in line ( $v$ ), each of the null hypotheses $B=1, \mu=0.5, \lambda=-1$, and $\eta=-1$ cannot be rejected by conventional criteria and these are precisely the parameter values implied if the 
union locals maximize the rents from unionization.15/ This does not appear to be an appropriate description of the objective function, however, for the group of relatively small union locals (line (vi)). A conventional test of the null hypothesis that the two groups of union locals have the same objective function parameters is decisively rejected.16/ Further disaggregation to the level of each individual union local seems not to be warranted, however. $17 /$

What appears to be a common finding in all the results in Table II is an estimate of the elasticity of substitution $(\sigma)$ between wages and employment in the ITU's objective function that lies between zero and unity. Only for the relatively imprecise estimates in line (iv) (in which both employment and output are endogenous) is $\sigma$ not significantly different from zero. In other words, these results are fully consistent with Cartter's conjecture that a union's objectives allow relatively little scope for substituting wages for employment. However, the limiting case of fixed wage and employment combinations also appears to be rejected by these estimates.18/

\section{v. Conclusions}

Two approaches to the issue of wage and employment determination in unionized labor markets can be identified. One approach takes the objectives of the trade union as given and enquires into the characteristics of the solution to the resulting bargaining problem Ide Menil, 1971; McDonald and Solow, 1981; Rosen, 19701. The second approach takes as a maintained hypothesis the method through which wages and employment 
are settled and investigates the objectives of the union [Dertouzos, 1979; Dertouzos and Pencavel, 1981; Farber, 19781. This paper has followed this second approach and has shown that, contrary to widespread belief, the questions involved in ascertaining the objectives of trade unions can be addressed through conventional empirical procedures. The union examined here is the ITU over the period 1946-65 and perhaps our most consistent finding is that the elasticity of substitution between wages and employment in the union's objective function tends to lie between zero and unity. This suggests quite restricted opportunities for trading off wages for employment. The larger ITU locals possess objectives that approximate the rents from unionization although it would be imprudent to attach a high degree of confidence to this inference in view of the standard errors accompanying the point estimates of the objective function parameters. Moreover, it should be stressed that the empirical implementation of the model requires specifications for two behavioral relationships, the union's objective function and the firm's labor demand function (or the first derivatives of both functions), and, therefore, estimates of the union's objective function parameters may be sensitive to the precise specification of the labor demand function $19 /$

What do these results suggest for the two empirical anomalies alluded to earlier, namely, the time series movements of wages in the printing industry and the variation in typographers' wages across different cities? Because bargaining takes place at the local level, it is not surprising that aggregative variables such as the unemployment 
rate in the entire economy are not highly correlated with movements over time of wages in the printing industry. On the other hand, the model of the wage-setting process outlined in this paper does identify the consumer price index as being relevant to money wage differences as should be differences in the exogenous variables of the labor demand function (such as the prices of other inputs and the factors determining newspaper output). If the objective functions of these union locals are characterized by little substitutability between wages and employment, then differences in the slope of the labor demand function will generate relatively small differences in (real) wages. In this event, the intercity variation in wages is a consequence of differences in the location of the labor demand function with, for instance, newspapers in big metropolitan areas with a larger circulation paying higher wages (which is exactly what is observed). On the other hand, if more observations on each union local were available, then the objective function parameter estimates in Table II might be more precisely estimated and significant differences across union locals might emerge. If this were the case, the observed intercity variation in wages would reflect, in part, the different weights attached to wages in the unions' objective functions and, then, an explanation for these variations in objectives would be called for.

A very large body of research now exists that applies constrained optimization models of the household and of the firm to data on consumption expenditure and production. In contrast, the literature on the behavior of the union became enmeshed in unproductive methodological 
squabbles and economists turned their interest towards the measurement of the various effects of unions without imbedding their measurement procedures in precisely articulated behavioral models. Consequently, there is a large body of research documenting the empirical regularities associated with unionism, but there is little interpretation of these regularities in terms of economic behavior. The primary purpose of this paper has been to show by way of example that purposive models of unionism (such as the one outlined here) have operational content and can be analyzed empirically.

Department of Economics, Stanford University, California National Bureau of Economic Research 
$\underline{\text { Footnotes }}$

* I am indebted to Paul Chen and Cathy Hartsog for their proficient research assistance, to Thomas MaCurdy, Andrew Oswald, and James Rosse for useful discussions during the preparation of this paper, and to two anonymous referees for their reactions to an early draft. I have also benefitted from a sloan Foundation grant to the Department of Economics at Stanford University.

1) For instance, in Wachter's [1970] time series analysis of wages in two-digit manufacturing industries, his preferred equation for the printing industry has only a time trend as a relevant regressor and no significant role is found for the unemployment rate, for price changes, and for movements in the industry's value added. Even more striking are the results reported by Eckstein and Wilson [1962] where $R^{2}$ 's for wage changes in the printing industry are recorded of 0.01 while most other industries generate $R^{2}$ s greater than 0.90 .

2/ The Bureau of Labor Statistics' wage surveys reveal that for hand compositors at night work in the newspaper industry workers in the city reporting the highest wage earned 55\% more in July 1946 and $28 \%$ more in July 1965 than workers in the city reporting the lowest wage. This range is all the more remarkable in view of the fact that these wage data relate to workers in a narrowly-defined occupation, the members of which possess very similar characteristics from city to city. (These data are published in BLS Bulletins No. 912 and No. 1489.)

3/ Indeed, even with further restrictions on the model, ambiguities prevail. For instance, suppose the slope of the labor demand function is independent both of wages and of the scale of production (i.e., suppose $\partial s / \partial w=\partial s / \partial X=0$ ). Then the effect on optimal wage of a proportional increase in output is $\partial \ln w / \partial \ln X=\sigma e_{x} L\left(g^{-1} g_{12}-g_{2}^{-1} g_{22}\right) /\left(1+s w L^{-1}\right)$ where $e_{x}$ is the elasticity of the demand for labor with respect to output, $g_{12}=\partial^{2} U / \partial w \partial L$, and $g_{22}=\partial^{2} U / \partial L^{2}$. If, in addition, the union's preferences are homogenous with respect to $w$ and $L$, then $\partial \ell n w / \partial \ell n X=\sigma e{ }_{X}{ }^{L g}{ }_{1}^{-1} g_{12}$. These expressions are ambiguous in sign. 
4) The adversaries in this debate were, of course, Dunlop [1944] who maintained, "An economic theory of a trade union requires that the organization be assumed to maximize (or minimize) something. Although not the only possible objective, maximization of the wage bill may be regarded as the standard case" (p. 4) and Ross [1948] who responded, "The wage policy of unions.... is not to be found in the mechanical application of any maximization principle" (p. 8).

5/ Cartter [1959, pp. 89-90] wrote: "It would seem most likely, once a union is already enjoying a particular wage-employment combination, that it would take a considerable increase in wages to compensate for a reduction in employment, and it would take a considerable increase in employment to compensate for a wage reduction. This is reasoned to be true because of the internal political pressures the union would be subject to if it openly agreed to either of these reductions."

6/ The justifications for these statements are to be found in the classic study by Lipset, Trow, and Coleman [1956].

1/ See Kelber and Schlesinger [1967]. Today the very survival of the ITU in its traditional form is threatened by the diffusion of typesetting computers and photographic processes which have eliminated many of the skills once required of printers. The dramatic consequences of this automation for New York's Local 6 are documented by Rogers and Friedman [1980].

8/ These data were obtained by James Dertouzos while consulting for the proprietors of the Cincinnati Post.

9/ Dertouzos [1979] and Dertouzos and Pencavel [1981] fitted the reduced form real wage equation jointly with the stochastic form of the employer's labor demand function. The estimates so derived were very similar to the maximum likelihood estimation of the reduced form real wage and employment equations as given in Pencavel [1982].

10/ Output is measured here by the amount of advertising linage sold annually and average values of this variable are listed in Table I. This output index measures only one dimension (albeit the most important in terms of newspaper revenues) of newpaper output and is not perfectly correlated with other dimensions such as the space devoted to news. Moreover, although many of the primary determinants of output are beyond the control of the newpaper firm 
(in particular, the size and wealth of a city's population and the number of television channels to which advertisers have access), it would be inappropriate to treat output invariably as exogenous. For these reasons, a set of estimates was derived for which output was characterized as endogenous. These are reported below.

11/ Thus, the labor demand function implied by this expression for $s$ is $L=f(\cdot)-(w / r)$ exp $(\alpha X)$ where $f(\cdot)$ is some unspecified function of $X, r$, and the prices of other inputs (except for w).

12/ The exogenous variables consist of $\log (p / r), x, w^{a} / p$, the wholesale price index of machinery and equipment and quadratic terms and interactions among these variables.

13/ The exogenous variables used to instrument for employment and output in this equation are $\log (p / r), w^{a} / p, \log q,\left(w^{a} / p\right)^{2}$, $(\log (p / r))^{2},(\log q)^{2}, T, T \cdot \log q, T \cdot \log (p / r)$, and $\mathrm{T} \cdot \mathrm{w}^{\mathrm{a}} / \mathrm{p}$ where $\mathrm{q}$ is a wholesale price index of machinery and equipment and $T$ is a time trend.

14/ For all these estimates, the quasi-concavity condition (equation (8)) was satisfied for all observations in the sample.

15/ The elasticity of substitution $(\sigma)$ is a highly nonlinear function of all the objective function parameters, however, so that, although each of the objective function parameters is not significantly different from the value assumed under the rent maximization hypothesis, $\sigma$ is significantly different from unity (which is the value taken by $\sigma$ is the union's objectives were exactly rent maximization).

16/ In this case, the calculated value of the $F$ statistic is 9.94 which exceeds by a large margin the critical value from the $F$ distribution.

17/ For the group of large union locals, the null hypothesis of no difference in the objective functions among the five locals yields a calculated $F$ of 1.52 while the corresponding value for the group of small union locals is 2.01. Each of these falls short of the 
critical $F$ value at the $1 \%$ percent level of significance. Of course, these test statistics are only approximate in this instrumental variable context.

18/ In equations fitted to each union local separately, a number of variations in the estimation procedure were applied to equation (9). First, the constraint that the slope of labor demand function be homogenous of degree minus unity in input prices was relaxed. Second, the equation was fitted in first difference form (year to year changes) with allowance for a linear time trend. Third, the objective function parameters were allowed to change after a merger between newspapers in those four cities in which a merger was recorded in these years. In each of these cases, the inferences about the objective function of the ITU were not materially different from those in the main text.

19/ Some examination of this issue was undertaken by specifying different slopes for the labor demand function. The resulting estimates of the union's objective function parameters were not substantially different from those reported above. 


\section{References}

Amemiya, T., "The Nonlinear Two-Stage Least Squares Estimator," Journal of Econometrics, II (July 1974), 105-10.

Archibald, G.C., "The Qualitative Content of Maximizing Models," Journal of Political Economy, LXXIII (February 1965), 27-36.

Cartter, Allan M., Theory of Wages and Employment, (Homewood, Ill.: Irwin, 1959).

de Menil, George, Bargaining: Monopoly Power Versus Union Power, (Cambridge, Mass.: MIT Press, 1971).

Dertouzos, J.N., "Union Objectives, Wage Determination, and the International Typographical Union," unpublished Ph.D. dissertation, Stanford University, December 1979.

Dertouzos, J.N., and J.H. Pencavel, "Wage and Employment Determination under Trade Unionism: The International Typographical Union," Journal of Political Economy, LXXXIX (December 1981), 1162-81.

Dunlop, John T., Wage Determination Under Trade Unions, (New York: Macmillan, 1944).

Eckstein, Otto, and Thomas A. Wilson, "Determination of Money Wages in American Industry," Quarterly Journal of Economics, LXXVI (August 1962), 379-414.

Farber, H.S., "Individual Preferences and Union Wage Determination: The Case of the United Mine Workers," Journal of Political Economy, LXXXVI (October 1978), 923-42.

Fellner, W., "Prices and Wages Under Bilateral Monopoly," Quarterly Journal of Economics, LXI (August 1947), 503-32.

Johnson, G.E., "Economic Analysis of Trade Unionism," American Economic Review, Proceedings, LXV (May 2975), 23-8. 
Kelber, H., and C. Schlesinger, Union Printers and Controlled Automation, (New York: Free Press, 1967).

Leontief, W.W., "The Pure Theory of the Guaranteed Annual Wage Contract," Journal of Political Economy, LIV (February 1946), 769 .

Lipset, S.M., M.A. Trow, and J.S. Coleman, Union Democracy: The Internal Politics of the International Typographical Union, (Glencoe, Ill.: Free Press, 1956).

McDonald, I.M., and R.M. Solow, "Wage Bargaining and Employment," American Economic Review, LXXI (December 1981), 896-908.

Oswald, A.J., "The Microeconomic Theory of the Trade Union," Economic Journal, 1982, forthcoming.

Pencavel, J.H., "The Empirical Performance of a Model of Trade Union Behavior," in J.J. Rosa, ed., The Economics of Trade Unions, 1982 forthcoming.

Rogers, T.F., and N.S. Friedman, Printers Face Automation, (Lexington Books, D.C. Heath and Co., 1980).

Rosen, S., "Unionism and the Occupational Wage Structure in the United States," International Economic Review, XI (June 1970), 269-86.

Ross, Arthur M., Trade Union Wage Policy. (Berkeley: University of California Press, 1948).

Wachter, M.L., "Relative Wage Equations for United States Manufacturing Industries 1947-1967," Review of Economics and Statistics, LII (November 1970), 405-10. 